\title{
Kinetic Analysis of Guanidine Hydrochloride Inactivation of $\beta$-Galactosidase in the Presence of Galactose
}

\author{
Charles O. Nwamba ${ }^{1}$ and Ferdinand C. Chilaka ${ }^{2}$ \\ ${ }^{1}$ Department of Chemistry, University of Idaho, 875 Perimeter Drive, MS 2343, Moscow, ID 83844-2343, USA \\ ${ }^{2}$ Department of Biochemistry, University of Nigeria, Nsukka, Enugu State 410001, Nigeria
}

Correspondence should be addressed to Charles O. Nwamba, charlesquemo@yahoo.com

Received 28 April 2012; Revised 28 July 2012; Accepted 29 July 2012

Academic Editor: Joaquim Cabral

Copyright (c) 2012 C. O. Nwamba and F. C. Chilaka. This is an open access article distributed under the Creative Commons Attribution License, which permits unrestricted use, distribution, and reproduction in any medium, provided the original work is properly cited.

\begin{abstract}
Inactivation of purified $\beta$-Galactosidase was done with $\mathrm{GdnHCl}$ in the absence and presence of varying [galactose] at $50^{\circ} \mathrm{C}$ and at $\mathrm{pH}$ 4.5. Lineweaver-Burk plots of initial velocity data, in the presence and absence of guanidine hydrochloride $(\mathrm{GdnHCl})$ and galactose, were used to determine the relevant $K_{m}$ and $V_{\max }$ values, with p-nitrophenyl $\beta$-D-galactopyranoside (pNPG) as substrate, $S$. Plots of $\ln \left([P]_{\infty}-[P]_{t}\right)$ against time in the presence of $\mathrm{GdnHCl}$ yielded the inactivation rate constant, $A$. Plots of $A$ versus $[S]$ at different galactose concentrations were straight lines that became increasingly less steep as the [galactose] increased, showing that $A$ was dependent on $[S]$. Slopes and intercepts of the $1 /[P]_{\infty}$ versus $1 /[S]$ yielded $k_{+0}$ and $k_{+0}^{\prime}$, the microscopic rate constants for the free enzyme and the enzyme-substrate complex, respectively. Plots of $k_{+0}$ and $k_{+0}^{\prime}$ versus [galactose] showed that galactose protected the free enzyme as well as the enzyme-substrate complex (only at the lowest and highest [galactose]) against $\mathrm{GdnHCl}$ inactivation. In the absence of galactose, $\mathrm{GdnHCl}$ exhibited some degree of non-competitive inhibition. In the presence of $\mathrm{GdnHCl}$, galactose exhibited competitive inhibition at the lower [galactose] of $5 \mathrm{mM}$ which changed to non-competitive as the [galactose] increased. The implications of our findings are further discussed.
\end{abstract}

\section{Introduction}

A folded protein does not exist in a single conformation, rather as a set of related conformations whose interconversion involves the making and breaking of the weak (noncovalent) interactions such as hydrogen bonds, van der Waals, salt bridges, and hydrophobic interactions that stabilize the folded structure of the protein. The range and speed of interconversions between the conformations will depend on the magnitudes of the relevant energy barriers. In essence therefore, the observed three-dimensional structure of a protein should be viewed as a weighted average of all the conformations accessible on the time scale in question [1] in specific environments. The folding energy landscape theory or the folding funnel concept, used to explain the principle of folding, suggests that the most realistic concept of a protein is a minimally frustrated heteropolymer with a funnel-like rugged energy landscape biased towards the native structure [2-6]. The ruggedness of the energy landscape is biologically essential, controlling the distribution of protein conformations along the biologically relevant landscape, not necessarily around the funnel bottom [7]. The structures of many enzymes are subject to conformational flux (changes/flexibility) during biological function and, thus, conformational fluctuations are coupled to catalysis [8]. The functional properties of enzymes are defined by the same interactions that define stability since they define not only the overall structure of a protein, but also the presence and location of regions with different propensities to undergo conformational rearrangements [9]. Thus, the stability of a protein depends on protein structure and function. The protein folding problem (Levinthal's paradox) deals with understanding how a protein searches its conformational space so quickly, attaining its native conformation within a very short period of time (microseconds or less) amidst the array of vast alternative conformers within its search frame [10] and, by implication, can be connected to protein stability [11] since the attained state is marginally stable compared 
to all other feasible conformations. Protein denaturation remains the primary source of information on the structural energetics of globular proteins and provides test data from which the contributions of the various interactions that stabilize the protein structure/function can be determined [12-14].

Unfolded peptides, polypeptides, and chemically unfolded proteins are flexible [15-17]. Flexible molecules exhibit conformational diversity. The more flexible the protein, the larger the ensemble of conformers. Such proteins can bind to a range of potential ligands and can be pictured as having a very rugged funnel bottom with rather low (induced fit) or high kinetic barriers (conformational selection) separating the multiple minima valleys [18, 19]. The conformer that binds a ligand is the one that is complementary to it, with the conformational equilibrium adjusting in favour of this conformer. While one conformation fits one ligand, an alternate conformer may be more favourable for binding a ligand with a different structure [20]. All these are mediated by changes in the environment of the molecule [19]. Thus, molecular flexibility enables the protein to bind to a range of potential ligands [18].

Ligand binding not only increases the rate at which denatured enzymes regain their activity during renaturation in their presence, but also maintain the native conformation of proteins during denaturation in their presence. This suggests that ligands act as a folding nucleus about which the remaining constructed regions are easily induced to assume a more biologically active conformation [21]. Recently, it has been suggested that ligands especially inhibitors can function as molecular chaperones [22]. Furthermore, there is also no doubt that a two-state binding process, in which binding and folding take place simultaneously, also displays a funnel-like shape [18]. The funnel arises because the drive towards a hydrophobic collapse (as in protein folding) is also a drive toward a reduced ensemble of conformations (as in both folding and binding where one conformation generally predominates) [5]. The binding of a ligand to a denatured protein could thus lead to the refolding of the protein with accompanying enzymatic activities [23]. In both folding and binding, the processes initiate from a higher energy and terminate in lower energy states, regardless of the pathways that are followed [18]. Folding and binding are connected by a common parameter: the energy landscapes.

We have recently shown that the conformational isomer taken up by a ligand-induced folding of a protein during denaturation is a function of the ligand type (product inhibitor) and concentration [23, 24]. We also showed that the galactose-induced refolding of $\beta$-galactosidase in the presence of urea was effected via different inhibition patterns. While folding is modulated by the solvent environment $[25,26]$, the peculiar binding energetics of an amino acid sequence in an unfolded polypeptide could enable the polypeptide attain well-defined structures [17]. We employed the analysis of Tian and Tsou [27], who suggested that, from the effect of $[S]$ on $A$, noncompetitive inhibition is involved when $A$ is independent of $[S]$, while a straight line will be obtained either in the plot of $1 / A$ against $[S]$ for

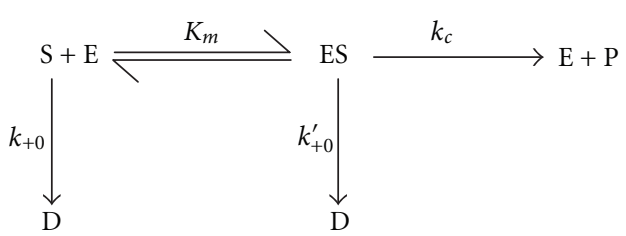

Scheme 1: $E, D, K_{m}, k_{c}, k_{+0}$, and $k_{+0}^{\prime}$ represent the native enzyme, denatured enzyme, the Michaelis constant, the turnover number of enzyme catalysed reaction in the presence of denaturant, the first order microscopic rate constant for the free enzyme, and the first order microscopic rate constant for the enzyme-substrate complex, respectively. All the kinetic constants are functions of the denaturant concentrations and thus functions of the apparent inactivation rate constant, $A$.

competitive inhibition, or $1 / A$ against $1 /[S]$ for uncompetitive inhibition. Alternatively, from the effect of $[S]$ on $[P]_{\infty}$, a competitive inhibition is predicted when a plot of $[P]_{\infty}$ against $[S]$ gives a straight line passing through the origin. For noncompetitive inhibition, the plot of $1 /[P]_{\infty}$ against $1 /[S]$ will be a straight line whereas for uncompetitive inhibition $[P]_{\infty}$ will be independent of $[S]$. In this work, we study the binding of galactose to $\beta$-galactosidase in the presence of the denaturant, $\mathrm{GdnHCl}$, and end with a summary of the import of our findings to the current knowledge of protein folding. Besides, we also contrast the relevance of our present findings from our previous work [23].

Theory. The kinetic analysis of the effects of substrate concentration on $\mathrm{GdnHCl}$ inactivation of Kestingiella geocarpa $\beta$-galactosidase in the presence and absence of galactose was a combination of the procedures of Xiao et al. [28] and Wang et al. [29]. The scheme of enzyme inactivation by denaturants in the presence of the substrate is as shown in Scheme 1 while the subsequent derivation of parameters and calculations relating enzyme inactivation by denaturants to product $(\mathrm{P})$ formation at given time intervals $t$ is as shown by Chilaka and Nwamba [23].

\section{Materials and Methods}

2.1. Materials. Fresh, dry, unwrinkled, and mature (Kestingiella geocarpa) seeds were bought from the Nsukka (Nigeria) main market. p-Nitrophenyl $\beta$-D-galactopyranoside (pNPG) and guanidine hydrochloride $(\mathrm{GdnHCl})$ used were purchased from Sigma Chemical company (St. Louis, MO, USA) and BDH (England), respectively. All other reagents used were of Analar grade.

2.2. Germination of Seeds. The seeds of Kestingiella geocarpa were germinated as already described in Chilaka and Nwamba [23].

2.3. Enzyme Extraction and Purification. The enzyme was extracted and purified according to the method of Chilaka et al. [24]. 
2.4. Protein Estimation. Protein concentration was determined by the method of Lowry et al. [30].

2.5. Enzyme Assay. Assay for enzyme activity after purification was carried out as described by Chilaka et al. [24].

\subsection{Effect of Substrate ( $p N P G$ ) Concentration on $\mathrm{GdnHCl}$} Inactivation of $\beta$-Galactosidase in the Presence and Absence of Galactose. The method of assay for the enzyme activity in the presence and absence of galactose is as already described by Chilaka et al. [24]. However, in this instance, the substrate concentration ranged from $0.10 \mathrm{mM}$ to $0.60 \mathrm{mM}$. The [galactose] employed in the study was from 5-20 mM. Briefly, the substrate, pNPG, and/or denaturant or substrate, denaturant and varying [galactose] were incubated at $50^{\circ} \mathrm{C}$ for 10 minutes in $0.10 \mathrm{M}$ sodium acetate buffer, $\mathrm{pH} 4.5$, while the enzyme was also incubated in a separate test tube, in the same buffer and at the same temperature. Substrate, denaturant, and galactose concentrations were calculated based on the total volume of the reaction vessels on introduction of the enzyme. Prior to the start of the experiment, aliquots were pooled off from the setup not containing the enzyme. This served as the blank. The reaction was started by introducing the enzyme into the test tube containing the substrate and/or denaturant or substrate, denaturant and galactose (all in the sodium acetate buffer) and one $\mathrm{mL}$ aliquots pooled off at varying time intervals and introduced into $4 \mathrm{~mL} \mathrm{NaOH}(0.10 \mathrm{M})$ to stop the reaction and develop colour. The absorbance of the solution was measured at $400 \mathrm{~nm}$ and the concentration of $\mathrm{p}$-nitrophenol released read off a p-nitrophenol standard curve. One unit of activity is the amount of enzyme liberating $1 \mathrm{mmol}$ of p-nitrophenol per minute.

\section{Results}

Lineweaver-Burk plot of initial velocity data of the native enzyme in the absence of Guanidine hydrochloride (GdnHCl) gave a $K_{m}$ of $0.25 \mathrm{mM}$ and a $V_{\max }$ of $15.48 \mu \mathrm{mole} /$ minute; while galactose was a competitive inhibitor with a $K_{i}$ of $26.0 \mathrm{mM}$ [24].

Time curves (plots of $[P]_{t}$ (p-nitrophenyl released versus the time, $t$ ) were plotted for $0,3 \mathrm{M}$-GdnHCl (Figures 1(a) and $1(\mathrm{~b}))$ in the absence of galactose, and for $3 \mathrm{M} \mathrm{GdnHCl}$ in the presence of $5 \mathrm{mM}, 10 \mathrm{mM}$ and $20 \mathrm{mM}$ galactose, respectively, (Figures $1(\mathrm{c})-1(\mathrm{e})$ ). The results showed that the concentration of product, $[P]([\mathrm{pNP}])$ formed at any time interval $t$, was directly related to the substrate concentration, $[S]([\mathrm{pNPG}])$. With increase in reaction time $t,[P]_{t}$ approached a constant value $[P]_{\infty}$, at each [pNPG]. However, in the presence of the $3 \mathrm{M} \mathrm{GdnHCl}$, the $[P]_{\infty}$ for each $[S]_{0}$ decreased with respect to that in the absence of the [GdnHCl] (Figures 1(a) and 1(b)). On introduction of the $5 \mathrm{mM}$ galactose, $[P]_{\infty}$ decreased drastically (Figure $1(\mathrm{c})$ ), but the $[P]_{\infty}$ dramatically increased through $10 \mathrm{mM}$ to $20 \mathrm{mM}$ galactose (Figures $1(\mathrm{~d})$ and $1(\mathrm{e})$ ). However, at $20 \mathrm{mM}$ galactose, the $[P]_{\infty}$ formed for the highest $[S]_{o}$ was still much lower to that formed in the presence of the $\mathrm{GdnHCl}$ alone. Actually, the $[P]_{\infty}$ for $3 \mathrm{M} \mathrm{GdnHCl}$ alone at $[S]_{o}$ of $0.60 \mathrm{mM}$ was over three times more than that formed when $20 \mathrm{mM}$ galactose was introduced. $3 \mathrm{M} \mathrm{GdnHCl}$ alone caused the $K_{m}$ to increase and $V_{\max }$ to decrease with respect to its absence. When the various [galactose] were introduced in the presence of the $\mathrm{GdnHCl}$, the $K_{m}$ increased for $5 \mathrm{mM}-10 \mathrm{mM}$ and decreased for $20 \mathrm{mM}$ galactose. The $V_{\max }$ from 5-20 mM galactose also followed this trend except the $5 \mathrm{mM}$ that had the lowest value compared to $\mathrm{GdnHCl}$ alone (Figure 2). Interestingly, the various $K_{m}$ in the presence of the [galactose] were all higher to that of the $\mathrm{GdnHCl}$ alone; while with the exception of the $10 \mathrm{mM}$ galactose, the $V_{\max }$ for the $3 \mathrm{M}$ $\mathrm{GdnHCl}$ was higher than those in the presence of galactose.

Plots of $\ln \left([P]_{\infty}-[P]_{t}\right)$ versus time $t$ (Figure 3 ) gave straight lines (first order kinetics) with slopes corresponding to $A$, the apparent inactivation rate constant. For ease of calculation and plotting, regression analysis was employed to calculate the slopes of the $\ln \left([P]_{\infty}-[P]_{t}\right)$ versus time plots. Plots of $A$ versus $[S]_{o}$ in the absence of galactose was zero order (Figure 4(a)), showing that the substrate had no protective effect on the enzyme inactivation. The value of $A$ for the $3 \mathrm{M} \mathrm{GdnHCl}$ was $0.0323 \mathrm{~s}^{-1}$. In the presence of galactose, plots of $A$ versus $[S]_{o}$ showed that $A$ was dependent on $[S]_{o}$, with a positive slope, which became increasingly less steep from $5 \mathrm{mM}$ to $20 \mathrm{mM}$ (Figure 4(b)). Experimentally, the type of inhibition can be ascertained by studying the effect of $[S]$ either on the apparent rate constant, $A$ or on $[P]_{\infty}$ [27]. The plot of $A$ against [galactose] shows that $3 \mathrm{M}$ $\mathrm{GdnHCl}$ alone (i.e., $0 \mathrm{mM}$ galactose) had the highest $A$ value when compared to those for the [galactose]. However, with respect to the [galactose], the value of $A$ rose slightly from $5 \mathrm{mM}$ through $10 \mathrm{mM}$ to $20 \mathrm{mM}$ (Figure $4(\mathrm{c})$ ). Plots of $[P]_{\infty}$ versus $[S]$ (Figure 5) gave straight lines passing near to the origin for the $5 \mathrm{mM}$ galactose (see insert in Figure 5). This indicated that the [galactose] was exhibiting a near competitive inhibition at the lower [galactose] of $5 \mathrm{mM}$ which changed to non-competitive as the [galactose] increased. The high intercept on the $y$-axis of the plot of $[P]_{\infty}$ versus $[S]$ for the $3 \mathrm{M} \mathrm{GdnHCl}$ alone indicates that the $\mathrm{GdnHCl}$ exhibited some degree of non-competitive inhibition on the enzyme.

Plots of $1 /[P]_{\infty}$ versus $1 /[S]_{o}$ at different [galactose] yielded $k_{+o}$ and $k_{+o}^{\prime}$. Plots of $k_{+o}$ and $k_{+o}^{\prime}$ versus [galactose] (Figure 6) showed that $k_{+o}$ versus [galactose] was a hyperbolic curve decreasing from $0.0305 \mathrm{~s}^{-1}$ to $0.0192 \mathrm{~s}^{-1}$, while $k_{+0}^{\prime}$ versus [galactose] gave a hyperbolic curve with $k_{+0}^{\prime}$ increasing from $0.0143 \mathrm{~s}^{-1}$ to $0.0292 \mathrm{~s}^{-1}$ and then decreasing to $0.0200 \mathrm{~s}^{-1}$ at [galactose] of $20 \mathrm{mM}$. This demonstrated a protection of the free enzyme as the [galactose] increased while the enzyme-substrate complex was protected, most especially, at the lowest and highest [galactose], respectively.

\section{Discussion}

During chemical or physical denaturation of many enzymes, inactivation may or may not parallel overall conformational changes [28]. With urea as the denaturant of $\beta$-galactosidase from $K$. geocarpa [23], it was suggested that inactivation 

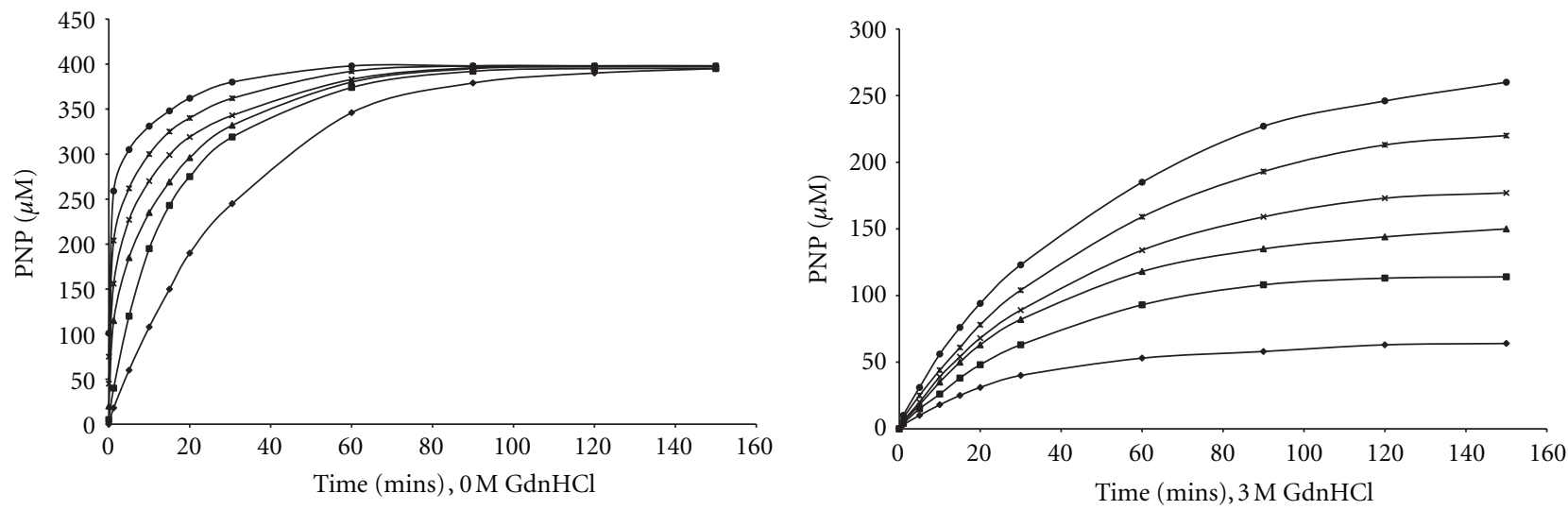

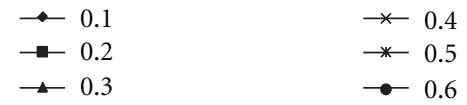

(a)

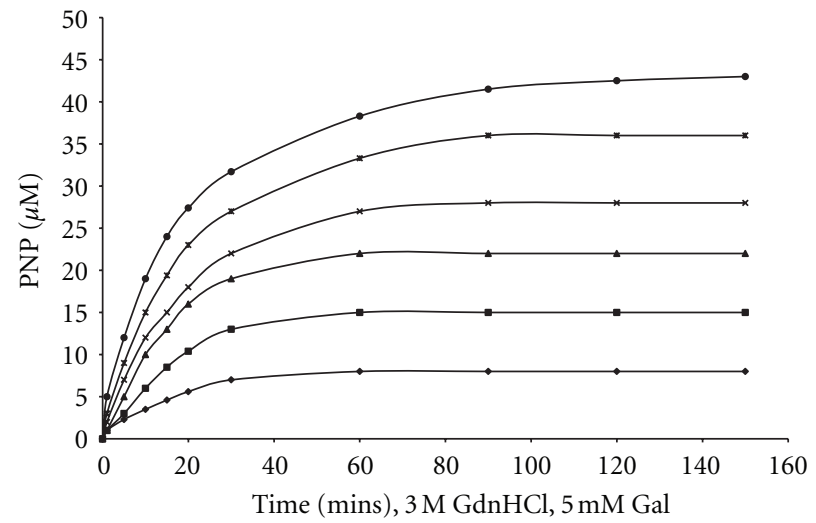

$\rightarrow 0.1$

$\rightarrow 0.2$

$\longrightarrow 0.3$

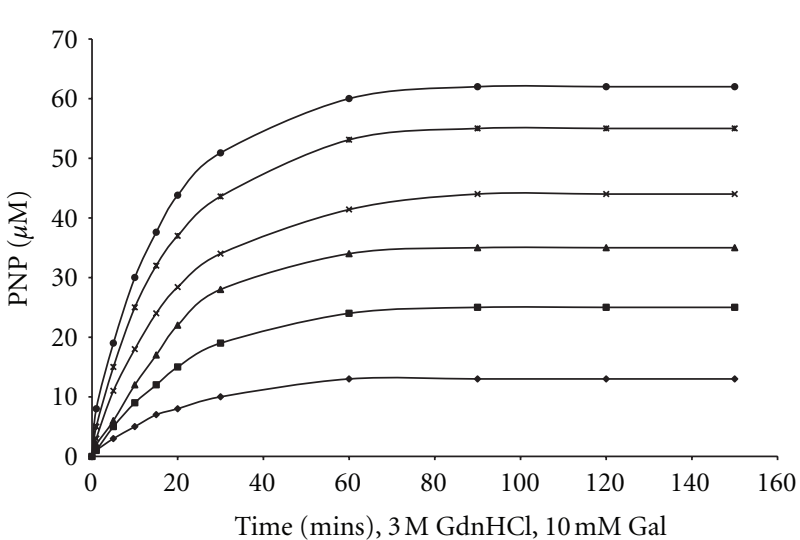

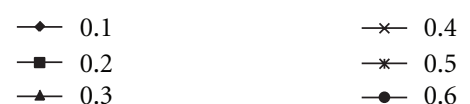

(c)

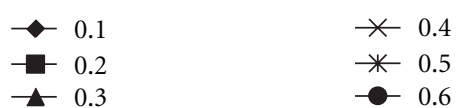

(d)
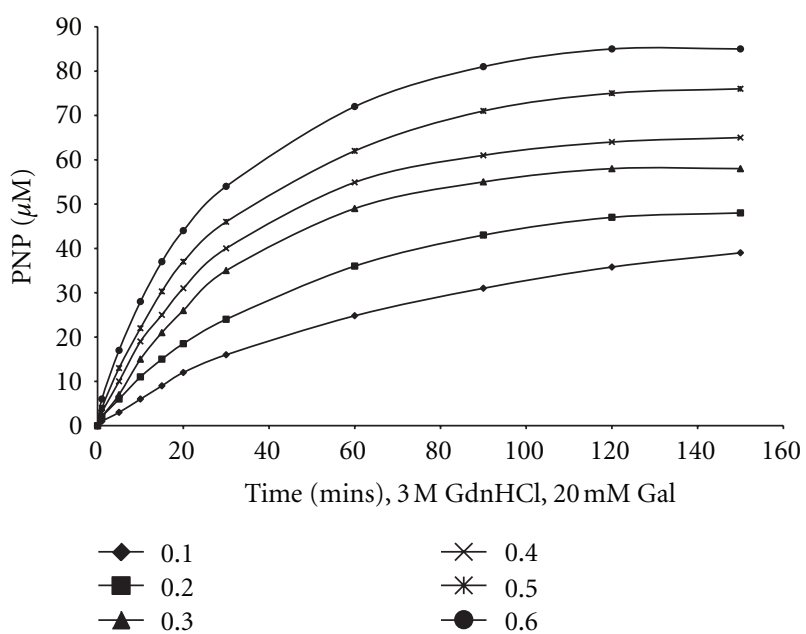

(e)

Figure 1: Kinetics of the inactivation of $\beta$-galactosidase in the absence and presence of $3 \mathrm{M} \mathrm{GdnHCl}$ at $50^{\circ} \mathrm{C}$, $\mathrm{pH} 4.5$, and at different concentrations of substrate, PNPG, [0.10-0.60]. (a) In the absence of $\mathrm{GdnHCl}$ (no GdnHCl); (b) in the presence of $3 \mathrm{M} \mathrm{GdnHCl}$; (c) in the presence of $3 \mathrm{M} \mathrm{GdnHCl}$ and $5 \mathrm{mM}$ galactose; (d) in the presence of $3 \mathrm{M} \mathrm{GdnHCl}$ and $10 \mathrm{mM}$ galactose; (e) in the presence of $3 \mathrm{M} \mathrm{GdnHCl}$ and $20 \mathrm{mM}$ galactose. 


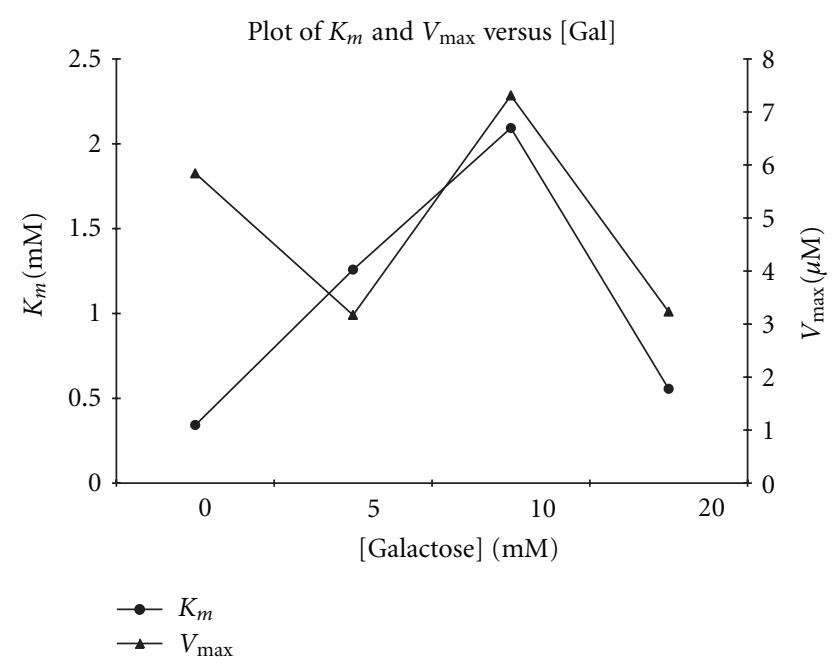

Figure 2: Effect of GdnHCl and galactose on the $K_{m}$ and $V_{\max }$ of $\beta$-galactosidase using pNPG as substrate, both in the presence and absence of galactose. $K_{m}$ and $V_{\max }$ values were calculated from Lineweaver-Burk plots of initial velocity data at the concentrations of $\mathrm{GdnHCl}$ and galactose indicated.

TABLE 1: The values of $k_{+0}$ and $k_{+0}^{\prime}$ for the corresponding concentrations of galactose.

\begin{tabular}{lcc}
\hline & $k_{+0}$ & $k_{+0}^{\prime}$ \\
\hline $3 \mathrm{M} \mathrm{GdnHCl} \mathrm{0} \mathrm{mM} \mathrm{Gal}$ & 0.0239 & 0.0111 \\
$5 \mathrm{mM}$ & 0.0305 & 0.0143 \\
$10 \mathrm{mM}$ & 0.0255 & 0.0292 \\
$20 \mathrm{mM}$ & 0.0192 & 0.0200 \\
\hline
\end{tabular}

occurred before measurable conformational changes, with the dominant inactivation/denaturation pathway involving changes in the enzyme active site. By employing a similar analysis, we have investigated the effect of $\mathrm{GdnHCl}$ on the kinetics of unfolding/refolding of $\beta$-galactosidase in the presence and absence of galactose.

In the presence of $\mathrm{GdnHCl}$, the $[P]_{\infty}$ at all $[S]_{o}$ decreased in comparison with the absence of the denaturant. This demonstrates the denaturing effect of the $\mathrm{GdnHCl}$ on the enzyme activity. The $5 \mathrm{mM}$ galactose drastically lowered the $[P]_{\infty}$ of the enzyme with respect to that in the presence of the $\mathrm{GdnHCl}$ and absence of galactose ( $0 \mathrm{mM}$ galactose). At this concentration of galactose as determined from the plot of $k_{+o}, k_{+o}^{\prime}$ versus [galactose], the dominant inhibition mechanism is the binding of the galactose to the enzyme via a competitive mode of inhibition. Characteristic of competitive inhibition was an increase in $K_{m}$, while the decrease in $V_{\max }$ shows that the inhibition mechanism was not wholly competitive. A reviewer of this paper brought to our notice a possibility that our results could also be due to nonproductive binding variant of competitive inhibition.

Compared to the $5 \mathrm{mM}$ galactose, the $10 \mathrm{mM}$ galactose had a higher partition ratio, $r\left([P]_{\infty} /[E]_{o}\right)$ and the highest $K_{m}$ and $V_{\max }$ values. Also at $10 \mathrm{mM}$ galactose, there was an enhanced non-competitive inhibition mechanism when compared to the $5 \mathrm{mM}$ galactose as seen from the intercepts on the $y$-axis of the plots of $[P]_{\infty}$ versus $[S]_{o}$. One consequence of a high $K_{m}$ is decrease in substrate specificity and decreased binding affinity, as a result of unstructuredness and increased flexibility of the enzyme active site induced by the GdnHCl. When $K_{m}>[S]_{o}$, the enzyme binds the substrate weakly and, therefore, the [ES] is present only at low concentrations. It has been suggested that, for the low $K_{m}$ binding processes with the tightly bound substrate, the ground state of the reaction is the ES complex, and the activation energy of the reaction is higher than for the high $K_{m}$ binding processes involving a weakly bound substrate in which the ground state of the reaction is the free reactants [31]. Thus, a low-energy enzyme-substrate complex is a "thermodynamic pit," from which the reaction has to climb out [31]. As high $K_{m}$ binding processes are incompatible with accumulation of intermediates but have the goal of maximizing the reaction rate, the predominant competitive inhibition mechanism at $5 \mathrm{mM}$ galactose where $K_{m}>[S]_{o}$ would prevail over the rate of product formation when compared with $10 \mathrm{mM}$ galactose which was less competitive and more non-competitive. The $20 \mathrm{mM}$ galactose exhibited, essentially, a non-competitive inhibition mechanism. As could be deduced from the plot of $K_{m}$ or $V_{\max }$ versus [galactose], the $10 \mathrm{mM}$ galactose signified the transition between a predominantly competitive (below $10 \mathrm{mM}$ ) and a predominantly non-competitive (above $10 \mathrm{mM}$ ) inhibition pattern. Although the $10 \mathrm{mM}$ galactose had a higher $V_{\max }$ compared to the $20 \mathrm{mM}$ galactose, the $20 \mathrm{mM}$ still had a higher partition ratio, $r$, compared to the $10 \mathrm{mM}$ galactose. This is not surprising since the galactose appears to enhance the effect of the $\mathrm{GdnHCl}$ on the free enzyme, although this effect appears inversely proportional to the [galactose] (see $k_{+o}$ column in Table 1 ). While the $A$ values from 5$20 \mathrm{mM}$ rose steadily, the $k_{+\mathrm{o}}$ and $k_{+\mathrm{o}}^{\prime}$ values decreased correspondingly from $5-20 \mathrm{mM}$ galactose except for the rise in the $k_{+o}^{\prime}$ value for $10 \mathrm{mM}$ galactose (Table 1). In fact at $20 \mathrm{mM}$, the galactose not only protected the free enzyme, but also conferred some protection on the [ES] with respect to that of the $10 \mathrm{mM}$ galactose. Probably, by binding and accumulation within the region of the active site (but not catalytic active site), the galactose was locally protecting the free enzyme and, partly, the enzyme-substrate complex, via a predominantly non-competitive inhibition mechanism, while the whole enzyme molecule was still being globally destroyed by the denaturant. In other words, as the galactose concentration decreased from the region of the enzyme active site, most probably to the interior of the molecule, the level of unstructuredness induced by the denaturant on the molecule increased. The $3 \mathrm{M} \mathrm{GdnHCl}$ alone (absence of galactose) had the least $k_{+\mathrm{o}}^{\prime}$ value, as well as having a $k_{+o}$ value higher than that of the $20 \mathrm{mM}$ galactose, yet it had the highest $A$ value when compared to those of the 5-20 mM galactose. This would indicate that, even though the substrate, pNPG, might confer about two times greater protection to the [ES] complex compared to the free enzyme $\left([E]_{o}\right)$ in the absence of galactose, however, it could not induce native structural reorganization that favored the native state formation. Furthermore, the plot of $A$ versus $[S]$ 


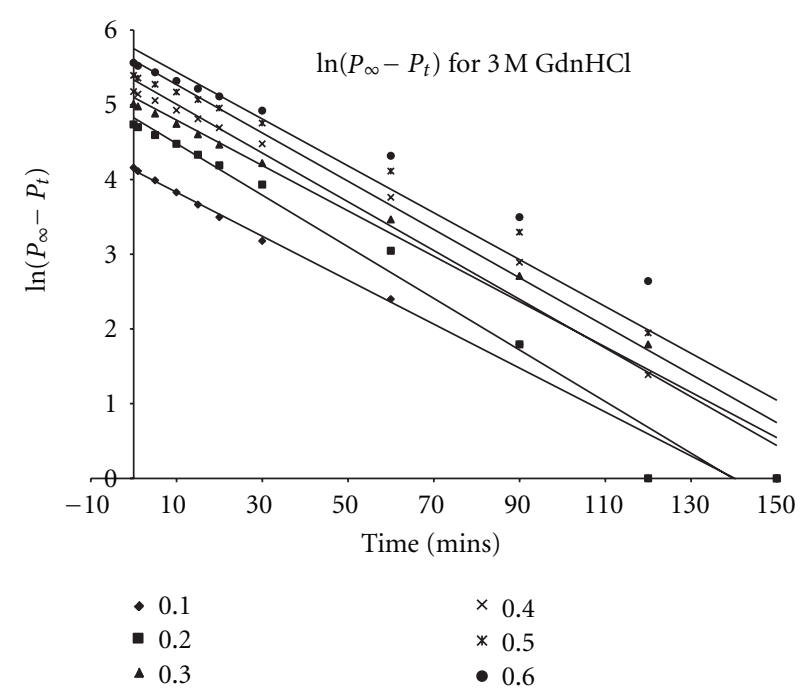

(a)

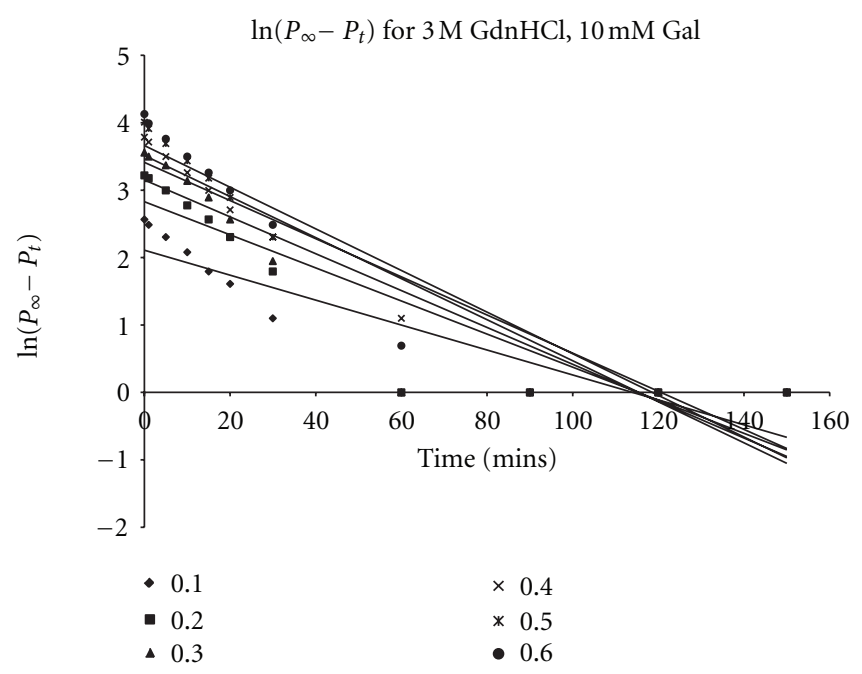

(c)

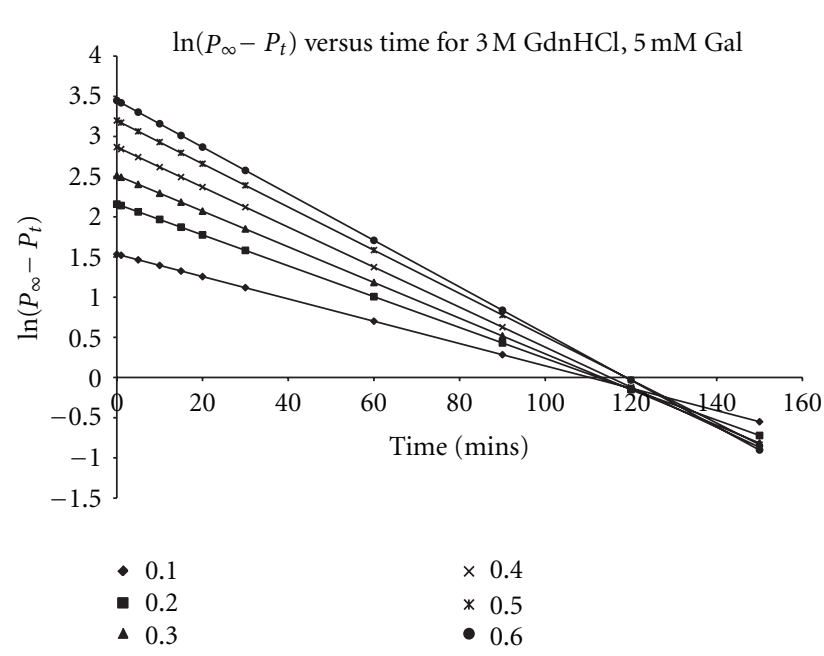

(b)

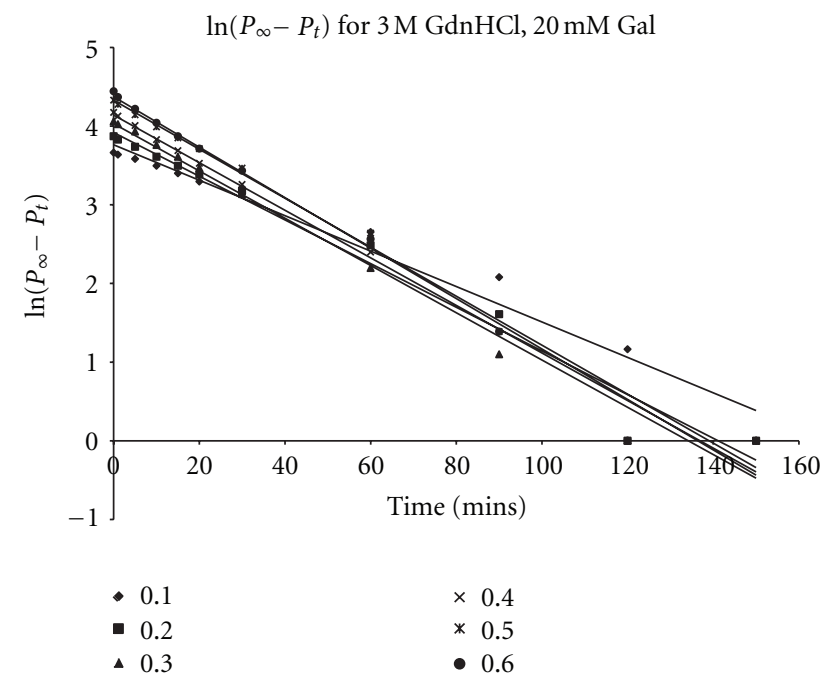

(d)

FIgURE 3: Semilogarithmic plot of $\mathrm{P}(\mu \mathrm{M})$ versus time $(t)$ of data: (a) $\ln \left([P]_{\infty}-[P]_{t}\right.$ ) versus $t$ for $3 \mathrm{M}$ GdnHCl, $0 \mathrm{mM}$ galactose; (b) $3 \mathrm{M}$ GdnHCl, $5 \mathrm{mM}$ galactose; (c) $3 \mathrm{M} \mathrm{GdnHCl}, 10 \mathrm{mM}$ galactose; (d) $3 \mathrm{M} \mathrm{GdnHCl}, 20 \mathrm{mM}$ galactose. N.B: $[P]_{\infty}=[\mathrm{pNP}] ;[P]_{t}=[\mathrm{pNP}]$.

for the $\mathrm{GdnHCl}$ was a zero order plot showing that on a global scale the substrate could not protect the enzyme; rather, it did so only at a local level (within the active site region).

In relation to the energy landscape, binding of the $[S]$ leads to catalysis via the modulation of the binding funnel towards reduced energy states with lower entropy, but with no apparent effect on the folding funnel. In other words, within the conformational equilibrium induced by the $3 \mathrm{M}$ $\mathrm{GdnHCl}$, the substrate binds and displaces the equilibrium towards a conformer or conformers with appropriate catalytic activity without the need to initiate global refolding. In the case of galactose, in an apparent paradox, even though the galactose (up to $10 \mathrm{mM}$ ) potentiated the inhibitory/inactivating effect of the $\mathrm{GdnHCl}$ on catalysis probably by synergism, it simultaneously modulated folding to a reduced ensemble of states as was seen by the decreased $A$ with respect to the absence of galactose and $3 \mathrm{M} \mathrm{GdnHCl}$. Above $10 \mathrm{mM}$, the full folding potential of galactose was realized, despite its inhibitory ability. Thus, a bit of catalytic proficiency was sacrificed for folding.

$\mathrm{GdnHCl}$ and urea perturb proteins by disintegrating the bonds needed to maintain the 3-dimensional (native) structure of the molecule. This leads to an uphill rise in the energy level of the molecule and an increase in its conformational entropy. Even though the number of protein conformations and potential binding sites grow dramatically with increasing steps up the energy ladder, Boltzmann's law dictates that the ligand prefers to choose from the relatively few ligation states low on the energy ladder [32]. Thus, even though high conformational entropy dictates a high number of energetically accessible states within a topology space, only a limited number of these states are energetically preferred [33]. As the bottom of the energy ladder narrows 


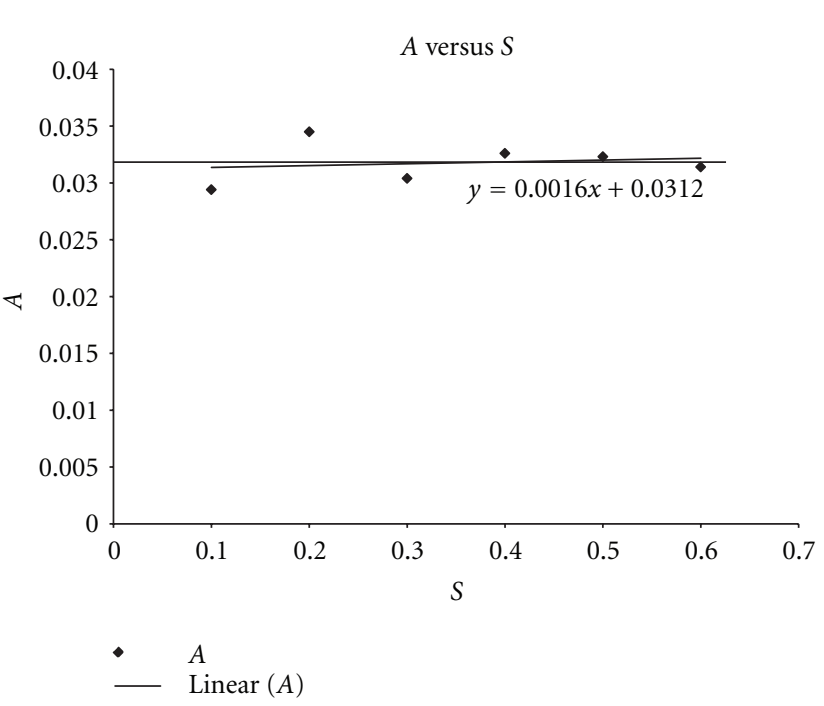

(a)

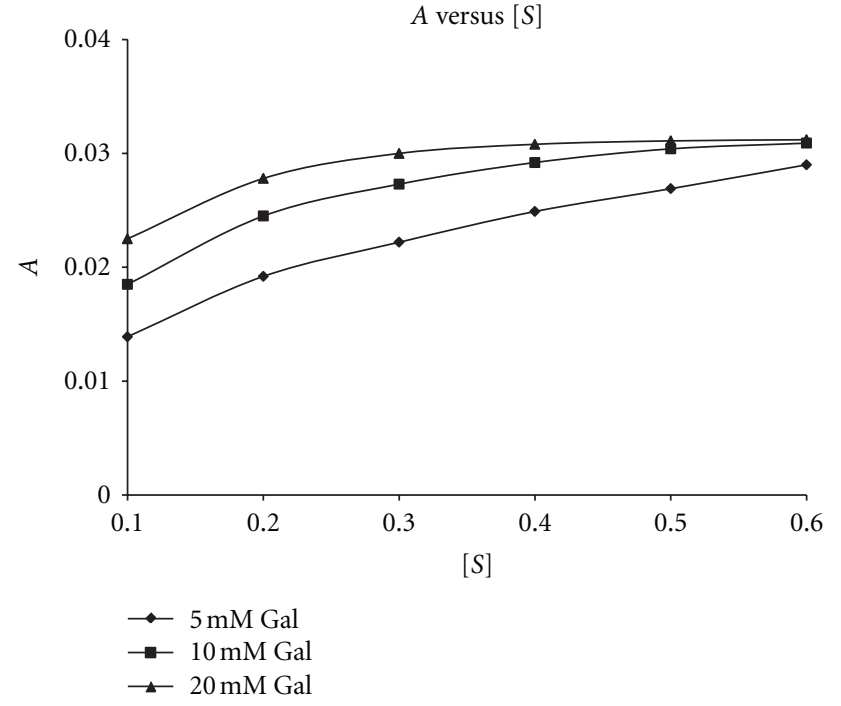

(b)

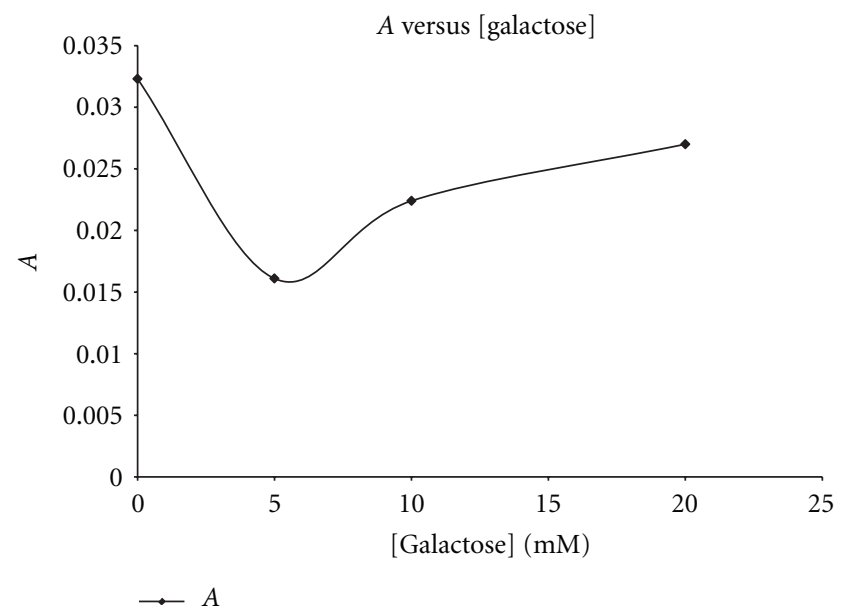

(c)

FIGURE 4: Plot of apparent inactivation rate constant $A$ against substrate (pNPG) concentration. (a) In the presence of $3 \mathrm{M}$ GdnHCl only; (b) in the presence of $3 \mathrm{M} \mathrm{GdnHCl}$ and all the [galactose]; (c) $A$ versus [galactose].

(the funnel concept), only molecules of low dimensionality and size would most probably bind to the few binding sites. Galactose, being able to fit more into the enzyme active site during catalysis of either the synthetic substrate, pNPG, or the natural substrate, lactose, would easily bind to different conformers of the enzyme when compared to the whole substrate molecule (pNPG) (or even lactose). Both pNPG and/or even lactose, due to greater bulk and thus, steric hindrance, would be limited in fitting into available enzyme conformers to modulate both binding and folding via shifts in the dynamic energy landscape which is a common denominator to both binding and folding. Thus, pNPG would not easily couple binding and folding as would galactose. In energy terms, galactose would readily bind to the low energy binding site(s) (as a function of concentration) to drive catalysis (via binding) and folding (since both binding and folding are geared towards a reduced ensemble of states), while pNPG would bind somewhere up the energy ladder to bring about a kinetic shift [19] to a local minimum that can only favour catalysis without been coupled to folding. The similarity of binding and folding is clear at the thermodynamic level, where both processes involve accurately locating molecular fragments with respect to each other, reducing the configurational entropy, and simultaneously lowering the free energy by the exclusion of solvent and formation of hydrogen bonds and salt bridges [34-36]. Thus, it could be understood why increasing [galactose] would have to wade through the sea of atoms of the enzyme molecule to the interior of the protein.

The action of the $\mathrm{GdnHCl}$ and urea creates some ruggedness around the bottom of the funnel (both binding and folding) $[19,32]$ that depicts various conformers. Ligandinduced isomerization [37] of the various enzyme conformers could be induced by galactose around the funnel 


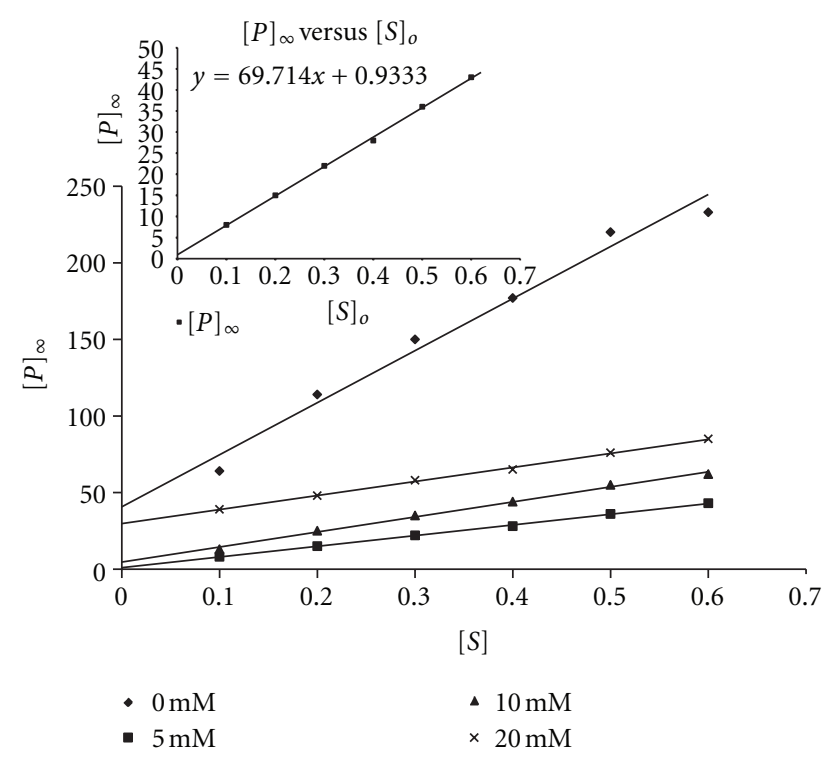

Figure 5: Plots of $[P]_{\infty}$ against $[S]$ for $\beta$-galactosidase in the presence of $3 \mathrm{M} \mathrm{GdnHCl}-5 \mathrm{mM}$ galactose, $3 \mathrm{M} \mathrm{GdnHCl}-10 \mathrm{mM}$ galactose, and $3 \mathrm{M} \mathrm{GdnHCl}-20 \mathrm{mM}$ galactose. Inset is the magnification of the graph of $[P]_{\infty}$ versus $[S]$ for $3 \mathrm{M} \mathrm{GdnHCl}-5 \mathrm{mM}$ galactose showing that the intercept on the $y$-axis is slightly above the zero point.

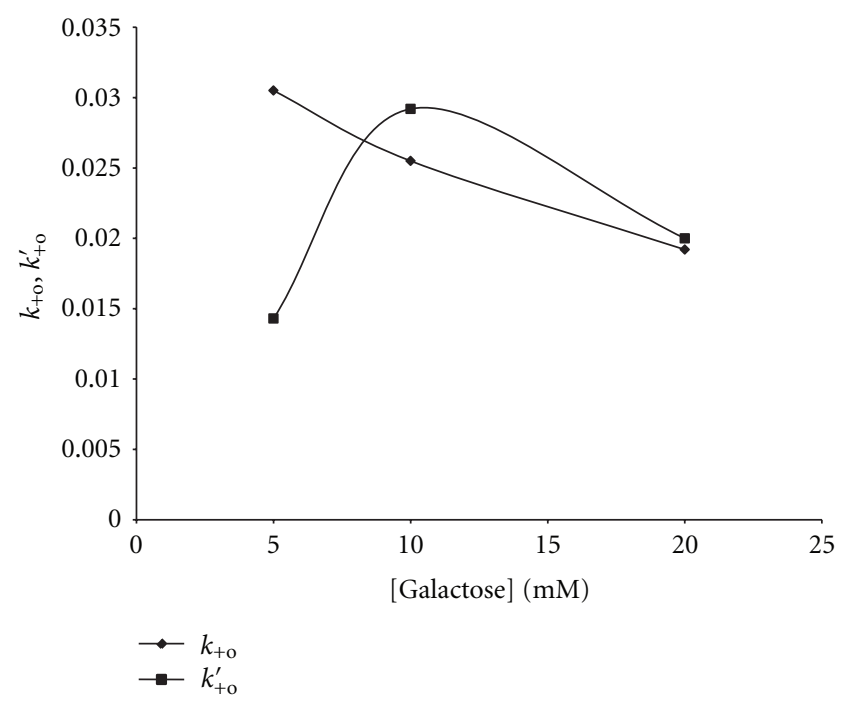

Figure 6: Plot of $k_{+o}, k_{+o}^{\prime}$ versus [galactose]. $k_{+o}$ and $k_{+o}^{\prime}$ are the microscopic inactivation rate constants for the free enzyme and enzyme-substrate complex, respectively.

bottom via different binding modes of inhibition modulated by the environment of the enzyme. This conformational reorganization around the funnel bottom is likely to be largely enthalpic rather than entropic [38], involving mainly residues backbone reorganization [39]. The ligand by binding to these conformers modulates the population shifts to redistribute around the predominating conformer (reviewed in [19]). The energy landscape which is dynamic could be shifted to favour a minimum with the population reequilibrating to that minimum, via an intermediary step populated mostly by secondary structural interactions and few tertiary interactions-the molten globule [23, 40-44]. Additionally, since the denaturants create the ruggedness in the funnel, then energetic frustration becomes a key factor in the coupled binding and folding mechanism. However, the ligand by selecting a conformation as modulated by its concentration eases off the ruggedness of the funnel so that minimal frustration accompanies the subsequent folding. From the plot of $K_{m}$ versus [galactose], it is clear that the various conformers have a high kinetic barrier between them since their $K_{m} S$ vary considerably. The ligand as a function of its concentrations binds to conformers most precise to a given concentration (conformational selection) and "pulls" the equilibrium via the dynamism of the energy landscape to favor the given conformer. We also suggest that since the $k_{+o}$ and the $k_{+o}^{\prime}$ decreased as the mode of inhibition became increasingly non-competitive (i.e., as the location of binding tilted more towards the hydrophobic core) while the $A$ increased, then there must be some sort of induced fit mechanism which propagates from the site of binding $[9,45]$ of the galactose to the exterior of the molecule so that as the galactose moves progressively inwards, the propagation of induced fit to the exterior diminishes and thus $A$ increases irrespective of the decreasing $k_{+o}$ and $k_{+o}^{\prime}$. Thus, galactose (unlike pNPG) effectively coupled binding to folding (so that folding occurred during binding), a trait characteristic of intrinsically unfolded or disordered proteins [46-48]. One selective advantage of folding only at the time of binding is the possibility to achieve high specificity with low affinity $[35,49]$. The [galactose] modulates specificity in the enzyme conformer that is selected, while the high $K_{m}$, as already discussed, tries to modulate catalysis so as to maximize rate by discouraging the accumulation of intermediates.

Urea, $\mathrm{H}_{2} \mathrm{~N}-\mathrm{CO}-\mathrm{NH}_{2}$ and $\mathrm{GdnHCl}, \mathrm{H}_{2} \mathrm{~N}-\mathrm{CNH}-\mathrm{NH} \cdot \mathrm{HCl}$, are known protein denaturants, but each induces different binding modes of inhibition. A comparison of the effect of urea [23] and $\mathrm{GdnHCl}$ (present communication) shows that the binding modes of inhibition are very opposite at the same concentrations of galactose. From the results of Scholtz et al. [50] on some model peptides, the interaction between urea and peptide groups account for a major part of the denaturing action of urea on proteins, and not by the interaction between urea and hydrophobic groups as earlier suggested [34]. Little wonder the dominant inactivation/denaturation pathway using urea on $\beta$-galactosidase from $K$. geocarpa involved changes in the enzyme active site, which of course is surface located. Thus, for a full protection/reactivation of the enzyme at high [galactose], the dominant binding mode of inhibition would have to involve competitive inhibition. In the case of $\mathrm{GdnHCl}$, in addition to possessing amino (as does urea) and imido groups, the denaturant possesses $\mathrm{HCl}$ which is strongly electrostatic/polar (however, since $\mathrm{GdnHCl}$ is a salt, it ionizes in solution as the $\mathrm{GuH}^{+}$and $\mathrm{Cl}^{-}$with the $\mathrm{GuH}^{+}$are the more potent charged group). Tsai and Nussinov [51] analyzed 294 salt bridges from a nonredundant data set of 38 high resolution $(\leq 1.6 \AA)$ crystal structures of dissimilar monomeric proteins. They found out that the majority (greater than three-quarters) of the salt 
bridges are formed within the hydrophobic folding units (domains). Thus, $\mathrm{GuH}^{+}$being strongly electrostatic would disorganize salt bridges in the core of the protein so that the dominant inactivation/denaturation pathway using $\mathrm{GdnHCl}$ would involve the hydrophobic core of the protein. Moreover, some thirty-eight years back, Greene and Pace [52] reasoned that since $\mathrm{GdnHCl}$ was 2.8 times more effective than urea (which is uncharged though polar) in unfolding ribonuclease but only 1.7 times more effective for lysozyme, then the more polar but buried polypeptide chain of the ribonuclease would have accounted for the greater denaturing capability of the $\mathrm{GdnHCl}$ on the ribonuclease to the lysozyme. However, since the dependence of conformational stability $\left(\Delta G_{D}\right)$ on $\mathrm{GdnHCl}$ concentration, $\delta\left(\Delta G_{D}\right) / \delta(\mathrm{GdnHCl})$, increases markedly as the denaturant concentration increases, then this indicates that an increase in the number of $\mathrm{GdnHCl}$ binding sites on unfolding is the major driving force for denaturation by $\mathrm{GdnHCl}$ [53]. Thus, it could be deduced as earlier proposed by Robinson and Jencks [54] and supported by further experimental works [55] that the strongest binding sites for $\mathrm{GdnHCl}$ or its ions on a protein molecule are the aromatic side chains and pairs of adjacent peptide groups by hydrogen bonding with the carbonyl groups. Thus, a proposed model for the denaturation of guanidinium-like species can be said to involve two processes: one, the disruption of water structure and the loosening of hydrophobic interactions and, the other, the solubilization of the interior of the protein due to specific interactions with the peptide bonds and solubilization of the hydrophobic regions [56]. Some years latter, Monera et al. [57] would suggest that since the masking effect of $\mathrm{GdnHCl}$ (at low concentrations) on electrostatic interactions (repulsions/attractions) that might be present in the protein would serve to underestimate the electrostatic contribution to stability, then the estimates of protein stability from $\mathrm{GdnHCl}$ denaturation studies would likely be a relative measure of the contributions of hydrophobic interactions. Consequently, measurable conformational changes would occur before enzyme inactivation during the enzyme denaturation. This might explain why the $3 \mathrm{M} \mathrm{GdnHCl}$ had the highest $[P]_{\infty} /[S]_{o}$ ratio any given time interval, $t$, in comparison to the presence of the galactose, while still possessing the highest $A$. Even though our $A$ values of $0.0161 \mathrm{~s}^{-1}-0.0323 \mathrm{~s}^{-1}$ compare favourably well with a value of $0.016 \mathrm{~s}^{-1}$ for papain, unlike in the work of Tian and Tsou [27] we cannot rule out a possible inactivation of the enzyme by inhibition from $\mathrm{GdnHCl}$. The plot of $[P]_{\infty}$ versus $[S]_{o}$ for the $3 \mathrm{M}$ $\mathrm{GdnHCl}$ shows that the $\mathrm{GdnHCl}$ was interacting via a noncompetitive binding mode with the enzyme that is away from the enzyme active site. However, from the nature of the slope of the $[P]_{\infty}$ versus $[S]_{o}$ plots for the $\mathrm{GdnHCl}$ alone, in comparison, to those in the presence of galactose, it becomes clear that site specific binding might not have been the only possible mode of binding for the GdnHCl. It is suggested that the solvent-exchange mode of interaction, in which the interactions of both the solvent (buffer) and the cosolvent $(\mathrm{GdnHCl})$ with the protein involve the interchange between the components at a particular interaction "site" on the protein $[50,58]$ could be operational. As the main

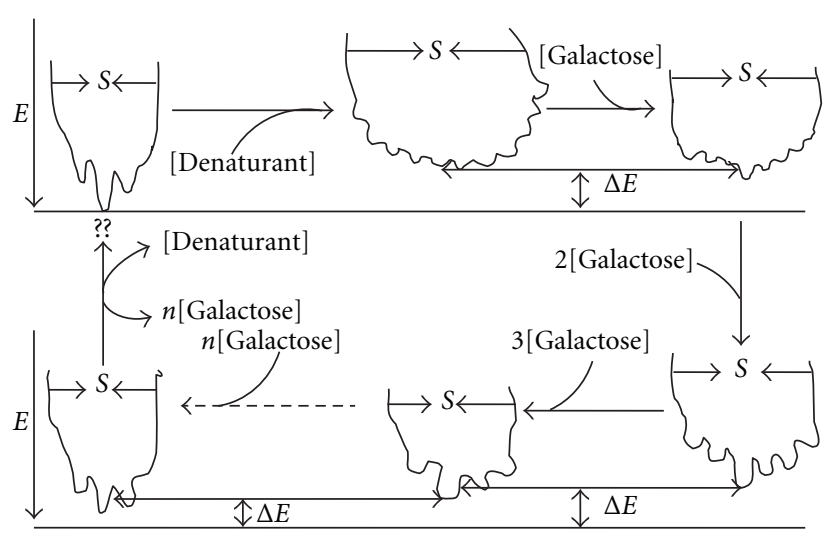

Scheme 2: The modulation of conformational substates by the galactose concentrations. $E$ is energy, $S$ is entropy, and $\Delta E$ is energy difference between two predominant conformational substates.

site of interaction of the $\mathrm{GdnHCl}$ with the protein is the hydrophobic core of the protein, the solvent-exchange system is inevitable.

We earlier noted the moonlighting properties of denatured $\beta$-galactosidase to model an intrinsically unstructured protein (IUP) via the modes of inhibition leading to reactivation using galactose [23]. Unlike conventional IUPs which use different sites for binding of the restructuring ligand and catalysis of its substrates to products, respectively [59], this protein could use either the same or different sites for both binding (and subsequently folding) and catalysis. While IUPs are involved in metabolic regulation $[46,47,59], \beta-$ galactosidase is also involved in metabolic regulation during seed germination and fruit ripening [60-62].

It is seen from Scheme 2 above that the denaturant creates some ruggedness around the funnel bottom, corresponding to different substates some of which would lead to misfolding of the protein where it (protein) is to be trapped in those substates. As the galactose is introduced, there is a decrease in the ruggedness on the folding funnel via a decrease in energy, entropy, and the number of the conformers (corresponding to different substates) with one conformer being predominant over the others. As [galactose] increases, the substates become fewer in number and even more distinct with the dominant conformation being all of the time more pronounced and with a lower energy to others around it. On removal of the [galactose] and [denaturant], the protein returns to the native state although in most cases the reformation of a native conformation is extremely slow or even impossible especially when the conformational changes are coupled to ionization reactions. It is seen that the [galactose] concentration modulates the enzyme forms present. The different enzyme forms bind to the substrate. The enzyme forms that bind $S$ apparently have the least $\Delta G$ at a given [galactose] in a local minimum which topologically favours the formation of a native state as a result of coupled binding and catalysis, as mediated by the ligand nature and concentration.

Below is a scheme suggesting the interconvertibility of the binding mode of $\beta$-galactosidase via the ligand concentration 
when unstructuredness is induced by a denaturant such as urea or $\mathrm{GdnHCl}$.

From Scheme 3, it is seen that the [galactose] (as well as the nature of the ligand [24]) modulates the enzyme forms present. Thus, different enzyme forms bind to the substrate at different [galactose]. The enzyme forms that bind $S$ are the enzyme forms that apparently have the least $\Delta G$ at a given [galactose] in a local minimum which topologically favours the formation of a native state as a result of coupled binding and catalysis, as mediated by the ligand nature and concentration.

We end our write-up with a summary of the relevance of our findings to the current knowledge of protein folding just as we contrast the relevance of our present findings from our previous work [23].

(a) Even though urea and $\mathrm{GdnHCl}$ are denaturants with some similarities in constituents, both refereed opposite binding and inhibition modes at same [galactose]. They do this basically by their interactions with the protein and varying [galactose], which results in different forces. It is these forces that determine the outcome of the interactions reflected as different inhibition mechanisms (see [10]). The contrasts between urea and $\mathrm{GdnHCl}$ actions highlight the importance of environment in determining the fate of a protein-from folding through functions, kinetics, and thermodynamics to denaturation and breakdown. This work illustrates the subtleties played out by various metabolites in the body and how these players might be the ultimate regulators between health and disease especially in the protein misfolding diseases such as sickle-cell disease where the conundrum that triggers polymerization and crisis is not immediately known $[63,64]$. It is possible that a subtle flux in environmental conditions could be the fine control (besides other fine controls such as epigenetics) and conformational gate keeper to polymerization.

(b) From our previous $[23,24]$ and present results, we deduce that both the natures of the denaturants and ligands, as well as the ligand concentrations at any given instance, were responsible for the mode of inhibition at given denaturant and ligand concentrations.

(c) Our present work suggests that hydrophilic interactions, even within hydrophobic folding cores, contribute substantially to the folding and stability of proteins. This is because the action of $\mathrm{GdnHCl}$ differed from urea by perturbing hydrophilic interactions within the protein cores. If these interactions within the folded core were of no importance to folding, stability, and function of the protein, then the inhibition mechanism and kinetics induced by urea and $\mathrm{GdnHCl}$ interactions with varying [galactose] would have been same or very similar to each other (see $[10,51]$ and some other sited references).

(d) Our results suggests that a so-called global minimum is not required for protein function. Once a protein has attained a minimum (local or global) and can function in its current state, then its attained Gibb's free energy for that state becomes its minimum even if it is in a metastable state. Thus, in vivo, many conformers of an enzyme may exist within a conformational/metabolic enclave, so that subtle environmental factors become the important parameters in a selection process making "the native state" a relative term and idiosyncratic.

(e) Jaffe's group [65] suggested that from our previous work [23], $\beta$-galactosidase probably exhibited the morpheein concept-the ability of a homooligomeric protein to exist as an ensemble of physiologically significant and functionally different alternate quaternary assemblies_coming apart and changing shape so as to convert between forms [66]. Hysteresis, hydrophilic interactions, and a scaffold or chaperoning action (such as the chaperoning effect of galactose in the presence of the denaturants) are all characteristics of morpheein proteins [66]. However, as suggested in our earlier work [23], $\beta$-galactosidase exhibited moonlighting protein properties, peculiar to intrinsically unstructured proteins (IUPs) (but certainly not restricted to IUPs) where such proteins are able to fulfill more than one, apparently unrelated function using different sites [67]. This raises a question: is it possible for $\beta$-galactosidase to moonlight and at the same time morph by breaking down into varying secondary structures, at different times, so as to convert into entirely new forms with different functionalities? Could it also be possible that $\beta$ galactosidase performs its metabolic regulatory activities [62] via the morpheein pathway? These are questions we do not have immediate answers to. However, the current concepts of moonlighting and morpheeins call for review of the $C$-value paradox [68] to account for the wide array of protein functions running under a limited number of genes.

(f) Small molecules as effectors (e.g., as activators or inhibitors, see [69]) due to a greater accessibility of sites can effectively act as interference molecules to modulate the preference of one pathway over the other. This is seen from the pNPG and galactose actions. Our results suggest that pNPG bound to the denaturant-perturbed enzyme to effect catalysis while galactose bound to fold and subsequently effect catalysis. This is apparent in the different conformations induced at different [galactose] (this did not occur for different [pNPG]).

\section{Conclusion}

In conclusion, the possible implications of our findings in vivo in biological systems might include (1) that enzyme catalytic sites (as the binding funnel) and hydrophobic cores (as the folding funnel) could be modulated by the ligand to give rise to different stable conformations of the enzyme. (2) The binding mode, which drives folding, is determined by 


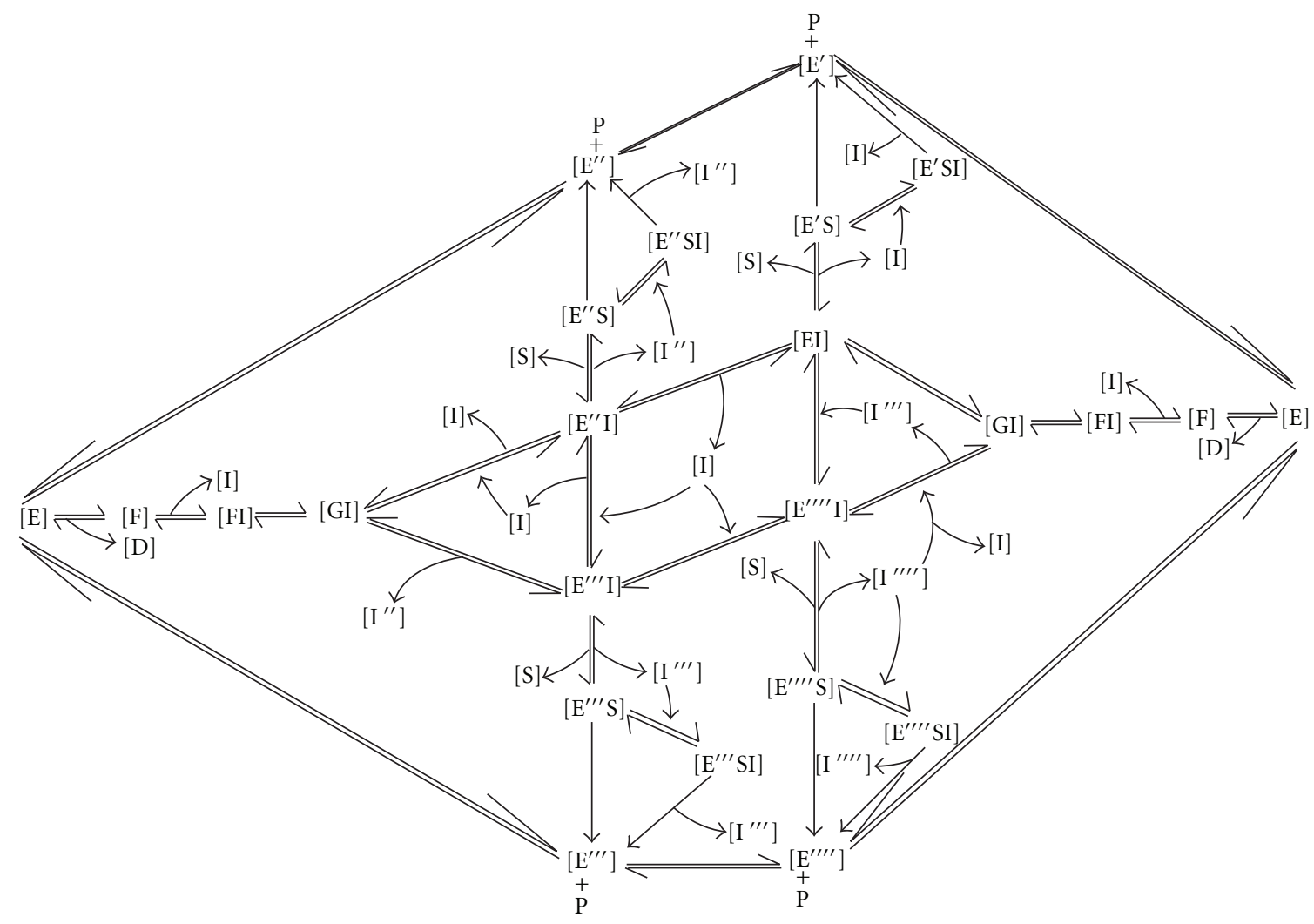

Scheme 3: Whereby E is the free/active enzyme form, ES, the enzyme-substrate complex, D is denaturant such as urea or GdnHCl; F, an inactive urea denatured enzyme form; $\mathrm{G}$, an intermediate enzyme form; $\mathrm{S}$, substrate. $\mathrm{I}^{\prime}, \mathrm{I}^{\prime \prime}, \mathrm{I}^{\prime \prime \prime}$, and $\mathrm{I}^{\prime \prime \prime \prime}$ are increasing concentrations of ligand (e.g., galactose), $\mathrm{E}^{n} \mathrm{~S}$ is enzyme-substrate complex whereby $n$ represents various conformational states of enzyme bound to substrate, $\mathrm{E}^{n} \mathrm{I}$ is enzyme-inhibitor complex whereby $n$ represents various conformational states of enzyme bound to inhibitor and $\mathrm{P}$, product, $\mathrm{E}^{n} \mathrm{SI}$ is enzyme-substrate-inhibitor complex whereby $n$ represents various conformational states of enzyme bound to substrate and inhibitor complex.

different forces arising from interaction sites. (3) Biological processes are carried out through binding, which respond to changes in the solvent environment. In different enzymes, the binding behaviour varies as a result of differences in structure/function and the environment.

\section{Conflict of Interests}

The authors declared that they have no conflict of interests.

\section{References}

[1] N. C. Price, "Conformational issues in the characterization of proteins," Biotechnology and Applied Biochemistry, vol. 31, no. 1, pp. 29-40, 2000.

[2] M. S. Cheung, L. L. Chavez, and J. N. Onuchic, “The energy landscape for protein folding and possible connections to function," Polymer, vol. 45, no. 2, pp. 547-555, 2004.

[3] A. Samiotakis, P. Wittung-Stafshede, and M. S. Cheung, "Folding, stability and shape of proteins in crowded environments: experimental and computational approaches," International Journal of Molecular Sciences, vol. 10, no. 2, pp. 572-588, 2009.
[4] M. C. Prentiss, D. J. Wales, and P. G. Wolynes, "The energy landscape, folding pathways and the kinetics of a knotted protein," PLoS Computational Biology, vol. 6, no. 7, Article ID e1000835, 2010.

[5] A. Schug and J. N. Onuchic, "From protein folding to protein function and biomolecular binding by energy landscape theory," Current Opinion in Pharmacology, vol. 10, no. 6, pp. 709-714, 2010.

[6] M. T. Oakley, D. J. Wales, and R. L. Johnston, "The effect of nonnative interactions on the energy landscapes of frustrated model proteins," Journal of Atomic, Molecular, and Optical Physics, vol. 2012, Article ID 192613, 9 pages, 2012.

[7] C. J. Tsai, B. Ma, Y. Y. Sham, S. Kumar, and R. Nussinov, "Structured disorder and conformational selection," Proteins: Structure, Function and Genetics, vol. 44, no. 4, pp. 418-427, 2001.

[8] D. D. Boehr, D. McElheny, H. J. Dyson, and P. E. Wrightt, "The dynamic energy landscape of dihydrofolate reductase catalysis," Science, vol. 313, no. 5793, pp. 1638-1642, 2006.

[9] E. Freire, "The thermodynamic linkage between protein structure, stability and function," in Protein Structure, Stability and Folding, Methods in Molecular Biology, K. P. Murphy, Ed., vol. 168, pp. 37-68, Humana Press, Totowa, NJ, USA, 2000.

[10] A. Ben-Naim, "Levinthal's paradox revisted, and dismissed," Open Journal of Biophysics, vol. 2, no. 2, pp. 23-32, 2012. 
[11] M. Niggemann and B. Steipe, "Exploring local and non-local interactions for protein stability by structural motif engineering," Journal of Molecular Biology, vol. 296, no. 1, pp. 181$195,2000$.

[12] A. A. Moosavi-Movahedi, K. Nazari, and A. A. Saboury, "Thermodynamics of denaturation of horseradish peroxidase with sodium $n$-dodecyl sulphate and $n$-dodecyl trimethylammonium bromide," Colloids and Surfaces B, vol. 9, no. 3-4, pp. 123-130, 1997.

[13] A. K. Bordbar, A. Nasehzadeh, D. Ajloo et al., “Thermodynamic elucidation of binding isotherms for hemoglobin \& globin of human and bovine upon interaction with dodecyl trimethyl ammonium bromide," Bulletin of the Korean Chemical Society, vol. 23, no. 8, pp. 1073-1077, 2002.

[14] A. K. Bordbar, A. A. Moosavi-Movahedi, and M. K. Amini, "A microcalorimetry and binding study on interaction of dodecyl trimethylammonium bromide with wigeon hemoglobin," Thermochimica Acta, vol. 400, no. 1-2, pp. 95-100, 2003.

[15] L. J. Lapidus, W. A. Eaton, and J. Hofrichter, "Measuring dynamic flexibility of the coil state of a helix-forming peptide," Journal of Molecular Biology, vol. 319, no. 1, pp. 19-25, 2002.

[16] L. J. Lapidus, P. J. Steinbach, W. A. Eaton, A. Szabo, and J. Hofrichter, "Effects of chain stiffness on the dynamics of loop formation in polypeptides. Appendix: testing a 1-dimensional diffusion model for peptide dynamics," Journal of Physical Chemistry B, vol. 106, no. 44, pp. 11628-11640, 2002.

[17] V. Muñoz, "Conformational dynamics and ensembles in protein folding," Annual Review of Biophysics and Biomolecular Structure, vol. 36, pp. 395-412, 2007.

[18] M. I. Zavodszky and L. A. Kuhn, "Side-chain flexibility in protein-ligand binding: the minimal rotation hypothesis," Protein Science, vol. 14, no. 4, pp. 1104-1114, 2005.

[19] S. Kumar, B. Ma, C. J. Tsai, N. Sinha, and R. Nussinov, "Folding and binding cascades: dynamic landscapes and population shifts," Protein Science, vol. 9, no. 1, pp. 10-19, 2000.

[20] J. Foote and C. Milstein, "Conformational isomerism and the diversity of antibodies," Proceedings of the National Academy of Sciences of the United States of America, vol. 91, no. 22, pp. 10370-10374, 1994.

[21] S. Sasso, I. Protasevich, R. Gilli, A. Makarov, and C. Briand, "Thermal denaturation of bacterial and bovine dihydrofolate reductases and their complexes with NADPH, trimethoprim and methotrexate," Journal of Biomolecular Structure and Dynamics, vol. 12, no. 5, pp. 1023-1032, 1995.

[22] Y. Qu, C. L. Bolen, and D. W. Bolen, "Osmolyte-driven contraction of a random coil protein," Proceedings of the National Academy of Sciences of the United States of America, vol. 95, no. 16, pp. 9268-9273, 1998.

[23] F. C. Chilaka and C. O. Nwamba, "Kinetic analysis of ureainactivation of $\beta$-galactosidase in the presence of galactose," Journal of Enzyme Inhibition and Medicinal Chemistry, vol. 23, no. 1, pp. 7-15, 2008.

[24] F. C. Chilaka, C. Okeke, and E. Adaikpoh, "Ligand-induced thermal stability in $\beta$-galactosidase from the seeds of the black bean, Kestingeilla geocarpa," Process Biochemistry, vol. 38, no. 2, pp. 143-149, 2002.

[25] P. Y. Chou and G. D. Fasman, "Conformational parameters for amino acids in helical, $\beta$-sheet, and random coil regions calculated from proteins," Biochemistry, vol. 13, no. 2, pp. 211222, 1974.

[26] P. Y. Chou and G. D. Fasman, "Prediction of protein conformation," Biochemistry, vol. 13, no. 2, pp. 222-245, 1974.
[27] W. X. Tian and C. L. Tsou, "Determination of the rate constant of enzyme modification by measuring the substrate reaction in the presence of the modifier," Biochemistry, vol. 21, no. 5, pp. 1028-1032, 1982.

[28] J. Xiao, S. J. Liang, and C. L. Tsou, "Inactivation before significant conformational change during denaturation of papain by guanidine hydrochloride," Biochimica et Biophysica Acta, vol. 1164, no. 1, pp. 54-60, 1993.

[29] Z. X. Wang, J. W. Wu, and C. L. Tsou, "The inactivation kinetics of papain by guanidine hydrochloride: a re-analysis," Biochimica et Biophysica Acta, vol. 1388, no. 1, pp. 84-92, 1998.

[30] O. H. Lowry, N. J. Rosebrough, A. L. Farr, and R. J. Randall, "Protein measurement with the Folin phenol reagent," The Journal of Biological Chemistry, vol. 193, no. 1, pp. 265-275, 1951.

[31] A. R. Fersht, "Optimization of rates of protein folding: the nucleation-condensation mechanism and its implications," Proceedings of the National Academy of Sciences of the United States of America, vol. 92, no. 24, pp. 10869-10873, 1995.

[32] D. W. Miller and K. A. Dill, "Ligand binding to proteins: the binding landscape model," Protein Science, vol. 6, no. 10, pp. 2166-2179, 1997.

[33] B. Ma and R. Nussinov, "Energy landscape and dynamics of the $\beta$-hairpin $\mathrm{G}$ peptide and its isomers: topology and sequences," Protein Science, vol. 12, no. 9, pp. 1882-1893, 2003.

[34] V. Prakash, C. Loucheux, S. Scheufele, M. J. Gorbunoff, and S. N. Timasheff, "Interactions of proteins with solvent components in $8 \mathrm{M}$ urea," Archives of Biochemistry and Biophysics, vol. 210, no. 2, pp. 455-464, 1981.

[35] R. S. Spolar and M. T. Record Jr., "Coupling of local folding to site-specific binding of proteins to DNA," Science, vol. 263, no. 5148, pp. 777-784, 1994.

[36] B. A. Shoemaker, J. J. Portman, and P. G. Wolynes, "Speeding molecular recognition by using the folding funnel: the flycasting mechanism," Proceedings of the National Academy of Sciences of the United States of America, vol. 97, no. 16, pp. 8868-8873, 2000.

[37] C. Frieden, "Kinetic aspects of regulation of metabolic processes. The hysteretic enzyme concept," Journal of Biological Chemistry, vol. 245, no. 21, pp. 5788-5799, 1970.

[38] C. M. Dobson, A. Sali, and M. Karplus, "Protein folding: a perspective from theory and experiment," Angewandte Chemie International Edition, vol. 37, no. 7, pp. 868-893, 1998.

[39] C. J. Tsai, A. del Sol, and R. Nussinov, "Allostery: absence of a change in shape does not imply that allostery is not at play," Journal of Molecular Biology, vol. 378, no. 1, pp. 1-11, 2008.

[40] V. N. Uversky and O. B. Ptitsyn, "'Partly folded' state, a new equilibrium state of protein molecules: four-state guanidinium chloride-induced unfolding of $\beta$-lactamase at low temperature," Biochemistry, vol. 33, no. 10, pp. 2782-2791, 1994.

[41] V. N. Uversky and O. B. Ptitsyn, "Further evidence on the equilibrium "pre-molten globule state": four-state guanidinium chloride-induced unfolding of carbonic anhydrase B at low temperature," Journal of Molecular Biology, vol. 255, no. 1, pp. 215-228, 1996.

[42] V. S. Pande and D. S. Rokhsar, "Is the molten globule a third phase of proteins?" Proceedings of the National Academy of Sciences of the United States of America, vol. 95, no. 4, pp. 14901494, 1998.

[43] R. L. Baldwin and G. D. Rose, "Is protein folding hierarchic? II. Folding intermediates and transition states," Trends in Biochemical Sciences, vol. 24, no. 2, pp. 77-83, 1999. 
[44] V. N. Uversky, "Natively unfolded proteins: a point where biology waits for physics," Protein Science, vol. 11, no. 4, pp. 739756, 2002.

[45] E. Freire, "The propagation of binding interactions to remote sites in proteins: analysis of the binding of the monoclonal antibody D1.3 to lysozyme," Proceedings of the National Academy of Sciences of the United States of America, vol. 96, no. 18, pp. 10118-10122, 1999.

[46] A. Caflisch, "Folding for binding or binding for folding?" Trends in Biotechnology, vol. 21, no. 10, pp. 423-425, 2003.

[47] G. M. Verkhivker, D. Bouzida, D. K. Gehlhaar, P. A. Rejto, S. T. Freer, and P. W. Rose, "Simulating disorder-order transitions in molecular recognition of unstructured proteins: where folding meets binding," Proceedings of the National Academy of Sciences of the United States of America, vol. 100, no. 9, pp. 5148-5153, 2003.

[48] K. Sugase, H. J. Dyson, and P. E. Wright, "Mechanism of coupled folding and binding of an intrinsically disordered protein," Nature, vol. 447, no. 7147, pp. 1021-1025, 2007.

[49] Y. Levy, P. G. Wolynes, and J. N. Onuchic, "Protein topology determines binding mechanism," Proceedings of the National Academy of Sciences of the United States of America, vol. 101, no. 2, pp. 511-516, 2004.

[50] J. M. Scholtz, D. Barrick, E. J. York, J. M. Stewart, and R. L. Baldwin, "Urea unfolding of peptide helices as a model for interpreting protein unfolding," Proceedings of the National Academy of Sciences of the United States of America, vol. 92, no. 1, pp. 185-189, 1995.

[51] C. J. Tsai and R. Nussinov, "Hydrophobic folding units derived from dissimilar monomer structures and their interactions," Protein Science, vol. 6, no. 1, pp. 24-42, 1997.

[52] R. F. Greene and C. N. Pace, "Urea and guanidine hydrochloride denaturation of ribonuclease, lysozyme, $\alpha$ chymotrypsin, and $\beta$ lactoglobulin," Journal of Biological Chemistry, vol. 249, no. 17 , pp. 5388-5393, 1974.

[53] C. N. Pace and K. E. Vanderburg, "Determining globular protein stability: guanidine hydrochloride denaturation of myoglobin," Biochemistry, vol. 18, no. 2, pp. 288-292, 1979.

[54] D. R. Robinson and W. P. Jencks, "The effect of compounds of the urea-guanidinium class on the activity coefficient of acetyltetraglycine ethyl ester and related compounds," Journal of the American Chemical Society, vol. 87, pp. 2462-2470, 1965.

[55] J. C. Lee and S. N. Timasheff, "Partial specific volumes and interactions with solvent components of proteins in guanidine hydrochloride," Biochemistry, vol. 13, no. 2, pp. 257-265, 1974.

[56] F. J. Castellino and R. Barker, "The effect of guanidinium, carbamoylguanidinium, and guanylguanidinium salts on the solubility of benzoyl-L-tyrosine ethyl ester and acetyltetraglycine ethyl ester in water," Biochemistry, vol. 8, no. 8, pp. 3439 3442, 1969.

[57] O. D. Monera, C. M. Kay, and R. S. Hodges, "Protein denaturation with guanidine hydrochloride or urea provides a different estimate of stability depending on the contributions of electrostatic interactions," Protein Science, vol. 3, no. 11, pp. 19841991, 1994.

[58] J. A. Schellman, "A simple model for solvation in mixed solvents. Applications to the stabilization and destabilization of macromolecular structures," Biophysical Chemistry, vol. 37, no. 1-3, pp. 121-140, 1990.

[59] P. Tompa, C. Szász, and L. Buday, "Structural disorder throws new light on moonlighting," Trends in Biochemical Sciences, vol. 30, no. 9, pp. 484-489, 2005.
[60] M. N. Fukuda, M. Fukuda, and S. Hakomori, "Cell surface modification by endo- $\beta$-galactosidase. Change of blood group activities and release of oligosaccharides from glycoproteins and glycosphingolipids of human erythrocytes," Journal of Biological Chemistry, vol. 254, no. 12, pp. 5458-5465, 1979.

[61] T. K. Biswas, "Characterization of $\beta$-galactosidases from the germinating seeds of Vigna sinensis," Phytochemistry, vol. 26, no. 2, pp. 359-364, 1987.

[62] Z. M. Ali, S. Armugam, and H. Lazan, "Beta-Galactosidase and its significance in ripening mango fruit," Phytochemistry, vol. 38, no. 5, pp. 1109-1114, 1995.

[63] F. C. Chilaka, C. O. Nwamba, and A. A. Moosavi-Movahedi, "Cation modulation of hemoglobin interaction with sodium n-dodecyl sulfate (SDS). I: Calcium modulation at pH 7.20," Cell Biochemistry and Biophysics, vol. 60, no. 3, pp. 187-197, 2011.

[64] C. O. Nwamba, F. C. Chilaka, and A. A. Moosavi-Movahedi, "Cation modulation of hemoglobin interaction with sodium n-dodecyl sulfate (SDS). II: Calcium modulation at pH 5.0," Cell Biochemistry and Biophysics, vol. 61, pp. 573-584, 2011.

[65] S. H. Lawrence, T. Selwood, and E. K. Jaffe, "Diverse clinical compounds alter the quaternary structure and inhibit the activity of an essential enzyme," ChemMedChem, vol. 6, no. 6, pp. 1067-1073, 2011.

[66] S. H. Lawrence and E. K. Jaffe, "Expanding the concepts in protein structure-function relationships and enzyme kinetics: teaching using morpheeins," Biochemistry and Molecular Biology Education, vol. 36, no. 4, pp. 274-283, 2008.

[67] C. J. Jeffery, "Molecular mechanisms for multitasking: recent crystal structures of moonlighting proteins," Current Opinion in Structural Biology, vol. 14, no. 6, pp. 663-668, 2004.

[68] G. P. Moore, "The C-value paradox," BioScience, vol. 34, pp. 425-429, 1984.

[69] E. K. Jaffe and S. H. Lawrence, "Allostery and the dynamic oligomerization of porphobilinogen synthase," Archives in Biochemistry and Biophysics, vol. 519, pp. 144-153, 2012. 

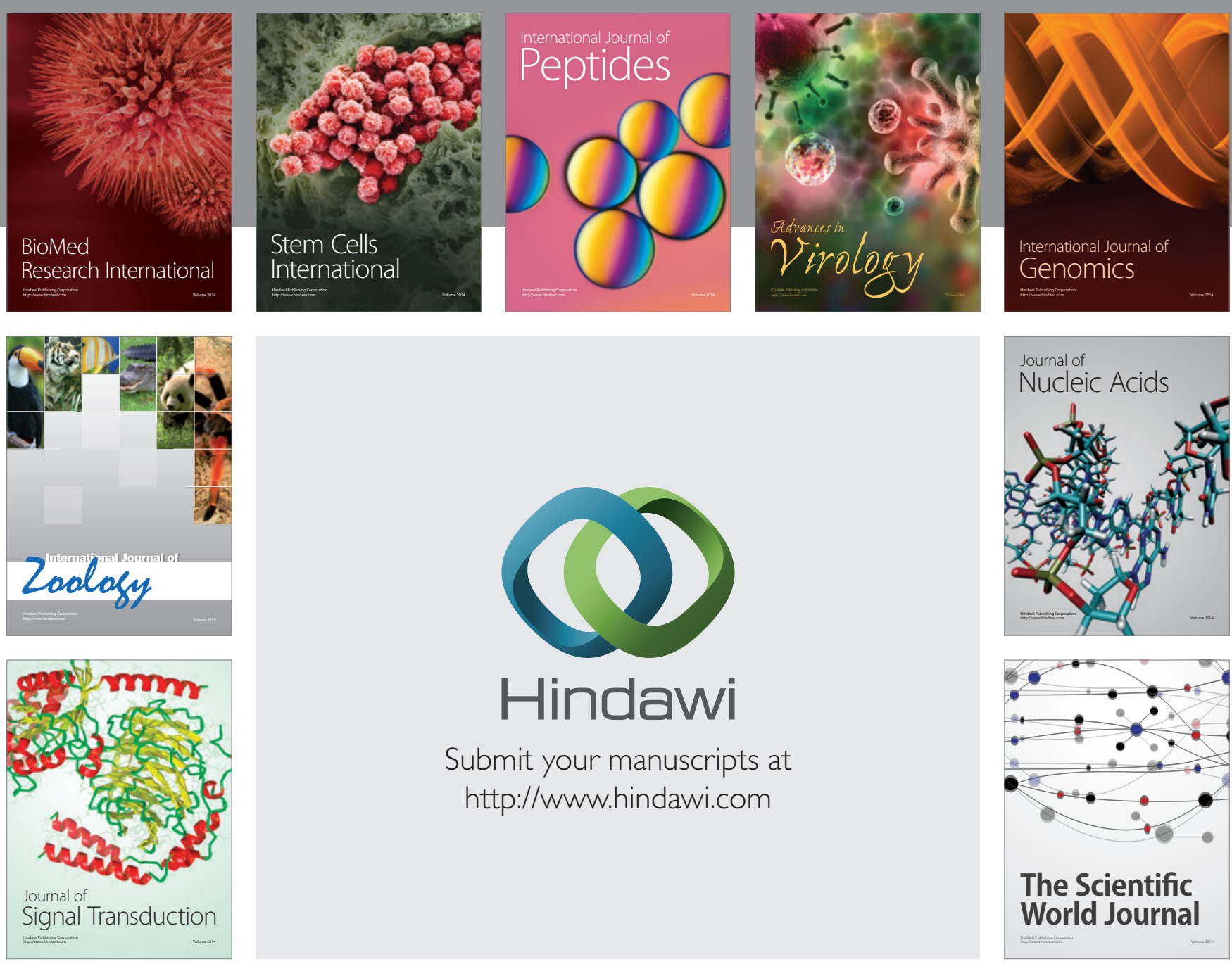

Submit your manuscripts at

http://www.hindawi.com
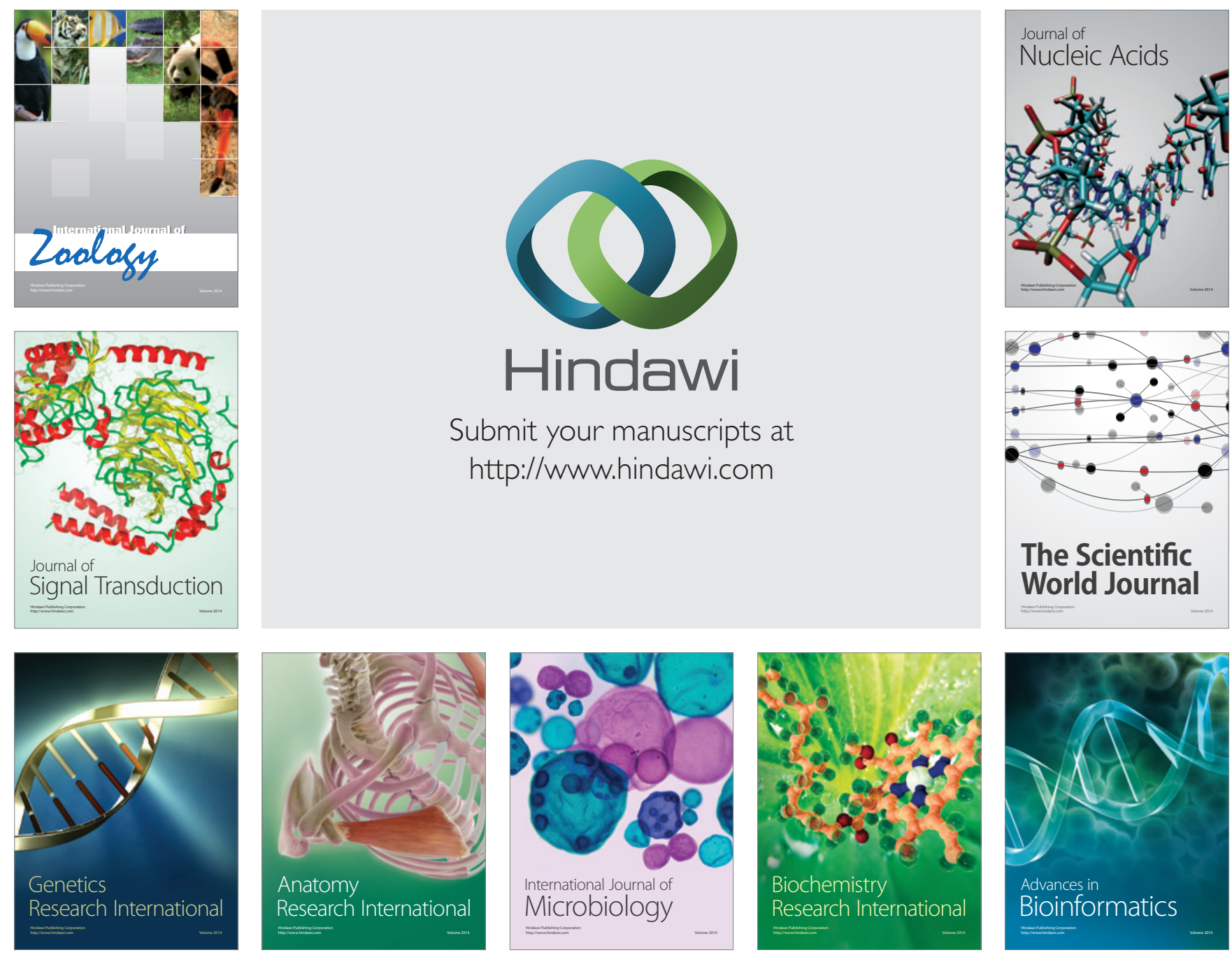

The Scientific World Journal
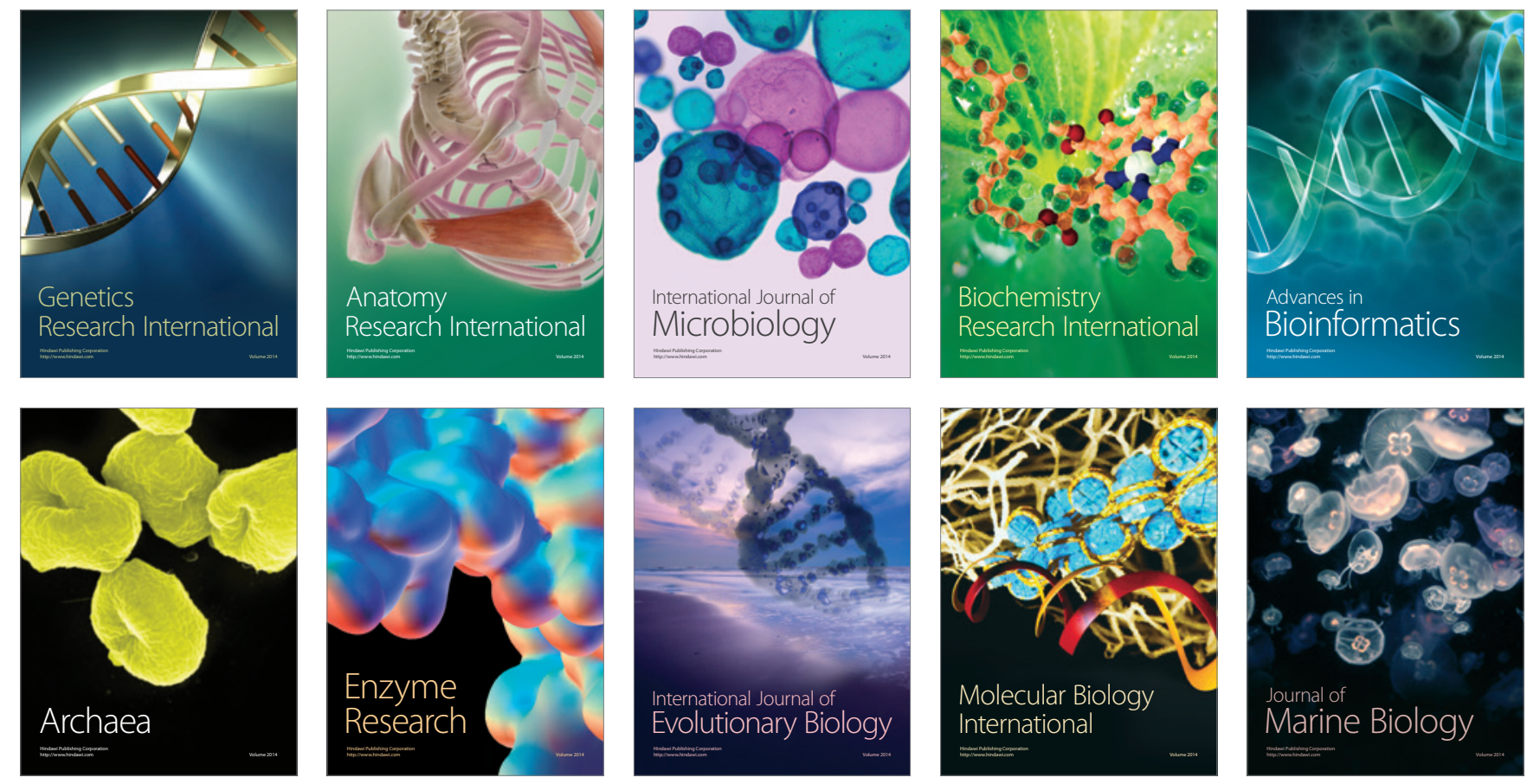